\title{
Pattern of Thyroid Cancer in the Eastern Province of Saudi Arabia: University Hospital Experience*
}

\author{
Ali M. Al-Amri \\ Department of Internal Medicine/Oncology, College of Medicine, University of Dammam, King Fahd Hospital of the University, \\ Al-Khobar, KSA. \\ Email: aliamri49@hotmail.com
}

Received March 16 ${ }^{\text {th }}, 2012$; revised April 10 ${ }^{\text {th }}, 2012$; accepted April 20 ${ }^{\text {th }}, 2012$

\begin{abstract}
Objectives: To review the pattern of thyroid tumor, demographic data of the patients, sensitivity, and specificity of fine needle aspiration cytology; Materials and Methods: This is a retrospective analysis of patients who underwent total or near-total thyroidectomy at King Fahad Hospital of the University between 1982 and 2008. Data were analyzed for demographic characteristics, type of thyroid tumors, Fine Needle Aspirations Cytology (FNAC) yields and surgical complications; Results: A total of 143 patients with thyroid tumors underwent throidectomy. Their median age was 37.5 years. Females were predominantly affected $(81 \%)$ with female to male ratio of $(4: 29)$. Thyroid carcinoma accounted for $(75 \%)$ while benign tumors for (25\%). The most common thyroid epithelial cancer was papillary type (74\%) and was limited to thyroid tissues in almost two third of cases. Non-epithelial cancer in the form of thyroid lymphoma accounted for (4.89\%) of the cases. FNAC sensitivity was 56\% and specificity $92 \%$. Surgical complications occurred in $18 \%$ of the patients; Conclusions: The commonest malignant thyroid cancer was papillary carcinoma. Thyroid cancer was more common in females. FNAC is highly accurate to confirm thyroid cancer but less sensitive in this study. Surgical complications were relatively minimal.
\end{abstract}

Keywords: Thyroid; Cancer; Saudi; Retrospective Study

\section{Introduction}

Clinically diagnosed thyroid cancer accounts for $6.1 \%$ of all newly diagnosed cases of cancer in Saudi Arabia and are ranked fourth in males and second in females with male to female ratio of 3.46:1 and the average age-specific incidence rate (AIR) in males is 1.6/100,000 and $5.1 / 100,000$ in females with an overall AIR of 3.3/ 100,000 [1].

Thyroid cancer is the most common of all endocrine malignancies, accounting for $87 \%$ of all endocrine gland tumors. Thyroid carcinoma though relatively rare, is the second most common cancer among Saudi women [1-4].

Fine Needle Aspiration Cytology (FNAC) is still the primary method for investigation of malignancy in patients with thyroid nodules and selecting patients for thyroid surgery [5-6].

Thyroid cancers have varied clinical presentations including solitary nodule or multi-nodular goiter. Other clinical manifestations include dysphagia, dyspnea or symptoms of thyrotoxicosis; however, typically they present as asymptomatic thyroid nodules in clinically euthyroid patients [7-9].

*There is no actual or potential conflict of interest.
Standard therapy of thyroid cancer includes total thyroidectomy, radioactive iodine ablation and thyroxine replacement in sufficient dose to suppress thyroid-stimulating hormone [8]. New therapies are being developed to target specific mutation pathways and intra-nuclear modulators of gene regulation.

The purpose of this study was to review the pattern of thyroid tumors in our area, their clinical presentation, demographic characteristics, sensitivity, and specificity of FNAC as well as surgical complications.

\section{Patients and Methods}

A retrospective review was conducted of all patients that underwent thyroid surgery between 1982 and 2008 at King Fahd Hospital of the University in the Eastern Province of Saudi Arabia. The data were collected from the admission and out-patients records of these patients, with review of their treatment and investigation charts including surgical notes, radiological, laboratory and histo-pathological reports. Patients with thyroid cancer proven by cytology or histopathology who underwent total or near-total thyroidectomy were included in this study. The study had the approval of the ethics committee of University Of Dammam. 
Thyroid neoplasm was staged as follows: Stage I: Cancer limited to thyroid; Stage II: Limited to lymph nodes; Stage III: With local invasion and Stage IV: With distant metastasis. Follow up included, an assessment of local relapse in remaining thyroid gland, neck lymph nodes or distant metastasis.

Pre-operative Fine Needle Aspiration Cytology (FNAC) when available was compared with postoperative histopathological diagnosis. There were 54 patients with FNAC reports prior to surgical interventions and post-operative histo-pathological reports as shown in Table 1.

\subsection{Histology}

All cases were reviewed and interpreted according to the 2004 WHO classification of thyroid tumors by one pathologist [10-11].

Histology included available positive or negative FNAC for malignant cells and surgical excision of thyroid lesions which were classified as: Benign: no maligant cells seen.

Malignant: positive for follicular, papillary, anaplastic and medullary carcinoma or lymphoma.

\subsection{Statistical Analysis}

The numbers of true-positive (TP), true-negative (TN), false-positive (FP) and false-negative (FN) results were calculated. Suspicious/malignant FNABs were considered as true positives (TP) in cases where post-operative reports revealed malignancy, and considered false positives (FP) if no malignancy was found. The benign FNAB report was considered as a true negative (TN) if post-operative reports were benign and false negative (FN) if it was reported as malignant. From these, the following statistical values were calculated as shown in Table 1.

percentage sensitivity: $(\mathrm{TP} / \mathrm{TP}+\mathrm{FN}) \times 100$

percentage specificity:

$$
(1-(\mathrm{FP} / \mathrm{FP}+\mathrm{TN}))(\mathrm{TN} / \mathrm{TN}+\mathrm{FP}) \times 100
$$

positive predictive value $(\mathrm{PPV}):(\mathrm{TP} / \mathrm{TP}+\mathrm{FP}) \times 100$

negative predictive value $(\mathrm{NPV}):(\mathrm{TN} / \mathrm{TN}+\mathrm{FN}) \times 100$

\section{Results}

Table 2 illustrates the demographic characteristic of patients with thyroid carcinoma. Sixty percent were Saudis and $40 \%$ non-Saudis. The median age was 38 years with a range of 14 to 85years; $81 \%$ were females. All patients presented with a neck mass, 20\% had dysphagia, 16\% neck pain, $12 \%$ dyspnea, $11 \%$ hoarseness, $3 \%$ symptoms of thyrotoxicosis and only $2 \%$ presented with weight loss. In $75 \%$, the diagnosis was confirmed as primary malignant carcinoma and 25\% showed benign disease. Epithelial thyroid carcinoma was seen in 100 patients with 74\% having papillary carcinoma. Seventy-three percent presented with the disease limited to thyroid tissue as shown in Table 3. Seven patients had primary thyroid lymphoma, stage I.
The available data of FNAC and histopathology reports were evaluated for sensitivity and specificity as shown in Table 1. Specificity was high (92\%) and negative predictive value (NPV) was 89.2\%. However, sensitivity was low (56\%) and positive predictive value (PPV) was $58.8 \%$. Surgical complications occurred in $18 \%$ of patients including one death as shown in Table 4.

Table 1. Association between FNAC and histopathology.

\begin{tabular}{cccc}
\hline Histopathology/FNAC & Carcinoma & Benign & Total \\
\hline Malignant & $\mathrm{TP}=10$ & $\mathrm{FP}=3$ & 17 \\
Benign & $\mathrm{FN}=8$ & $\mathrm{TN}=33$ & 37 \\
Total & $\mathbf{1 8}$ & $\mathbf{3 6}$ & $\mathbf{5 4}$ \\
\hline
\end{tabular}

Sensitivity $=$ TP $/ \mathrm{TP}+\mathrm{FN}=10 / 10+8=56 \%$; Specificity $=\mathrm{TN} / \mathrm{TN}+\mathrm{FP}=$ $33 / 33+3=92 \% ; \mathrm{PPV}=10 / 17=58.8 ; \mathrm{NPV}=33 / 37=89.2$.

Table 2. Demographic characteristics of patients with thyroid carcinoma.

\begin{tabular}{cc}
\hline Characteristics & No. (\%) \\
\hline Nationality & $86(60)$ \\
Saudi & $57(40)$ \\
Non-saudi & \\
Age & \\
Range 14-85 yrs & \\
Median 37.8 yrs & \\
Sex & $116(81)$ \\
Female & $27(19)$ \\
Male & \\
Presenting symptoms & $143(100)$ \\
Neck mass & $22(20)$ \\
Dysphagia & $17(16)$ \\
Pain & $13(12)$ \\
Dyspnea & $12(11)$ \\
Hoarseness & $3(3)$ \\
Thyrotoxicosis & $2(2)$ \\
Weight loss & $36(25.17)$ \\
Type of thyroid tumors & $100(69.93)$ \\
Benign & $7(4.89)$ \\
Carcinoma & \\
Lymphoma &
\end{tabular}

Table 3. Histological type and staging of thyroid tumors.

\begin{tabular}{cc}
\hline Primary thyroid cancer & No. (\%) \\
\hline Type of carcinoma & $100(100)$ \\
Papillary & $74(74)$ \\
Follicular & $14(14)$ \\
Hurthle cells & $7(7)$ \\
Anaplastic & $5(5)$ \\
Stage & \\
Limited to thyroid tissues & $77(73)$ \\
Lymph node involvement & $21(20)$ \\
Distant metastasis & $8(7)$ \\
Type of Lymphoma & $7(100)$ \\
Follicular lymphoma & $71.43 \%$ \\
DLBL(diffuse large B-cell lymphoma) & $28.57 \%$ \\
\hline
\end{tabular}

*Benign lesion excluded; ** Primary lymphoma of thyroid stage I. 
Table 4. Complications of surgery.

\begin{tabular}{lc}
\hline Complications & No. (\%) \\
\hline Death & $1(0.07 \%)$ \\
RLNP & $10(7.35 \%)$ \\
Hypothyroidism & $2(1.47 \%)$ \\
Hypoparathyroidism & $1(0.07 \%)$ \\
Recurrence of thyroid cancer & $12(8.8 \%)$ \\
Local & $8(5.9 \%)$ \\
Distant & $4(2.9 \%)$ \\
\hline
\end{tabular}

RLNP: recurrent laryngeal nerve palsy; ${ }^{*}$ Follow up 3 years.

\section{Discussion}

Thyroid cancer is the commonest malignant endocrine tumor but comprises only about $1 \%$ of all malignancies and typically presents as unilateral painless thyroid nodule in a clinically euthyroid patient. In Saudi Arabia, thyroid carcinoma was responsible for $6.1 \%$ of all newly diagnosed cancer in the Year 2004 and ranked second among female population [1]. Female to male ratio was reported as $2.66: 1$ but in our study, the ratio was $4.29: 1$. In contrast, the western region of Saudi Arabia, there was slight male predominance with male to female ratio of 1.1:1 [12].

The median age of our patients was 37.8 years similar to Saudi registry of cancer [1]. Younger age at presentation was reported in Yemen and other studies in Saudi in whom two thirds of the patients were younger than 40 years [13-15].

Our study showed that all of the patients presented with thyroid gland nodules with infrequent local compressive symptoms such as dysphagia, dyspnea and hoarseness. These symptoms are not specific for malignant diseases and may present in benign conditions or absent in malignnant conditions [15-17]. Benign lesions accounted for only 25\%. Other non-malignant lesions such as, simple goiter, thyroididtis, granuloma, lipoma and cyst were excluded from our analysis.

In this study, papillary carcinoma was more frequent than the other variant of thyroid carcinoma, and accounted for $74 \%$. This histo-pathologic distribution of thyroid cancer is comparable to international literature, as well as with what has been reported previously from Saudi Arabia [1,3,12,14,16-18].

Papillary carcinoma has been reported as the commonest malignant thyroid tumor with a variable frequency of $57 \%$ to $93 \%[16,19-25]$. It is interesting to note that papillary carcinoma of thyroid gland varied in many studies accounting for 60\% in Pakistan, 63.6\% in France, 87\% in Spain and $100 \%$ in India.

Medullary thyroid carcinoma accounts for approximately $4 \%$ of all thyroid cancers in the United States [26]. It was not observed in our study. This could be due to under diagnosis, small sample size of our study or probably genetic reasons.

Primary lymphoma of thyroid is rare. However, it should always, be considered in the differential diagnosis of patients with thyroid tumors since its therapy and prognosis differs from those of other thyroid malignancies. Primary thyroid lymphomas represents $1 \%$ - 5\% of all malignant thyroid tumors $[27,28]$. In our study, primary thyroid lymphoma, primarily, diffuse large B-cell lymphoma accounted for $4.89 \%$ of malignant thyroid tumors.

Since its introduction in 1952, Soderstran had established the FNAC biopsy as a safe, simple, reliable and invaluable method for preventing unnecessary surgery. Nowadays FNAC is the diagnostic investigation of choice in the majority of thyroid clinics and the single most accurate method for differentiating benign from malignant thyroid nodules [3,18,29-31].

In this study, FNAC showed sensitivity of $56 \%$, specificity of $92 \%$, positive predictive value of $58.8 \%$ and negative predictive value of $89.2 \%$. These results are comparable to data from other studies [32].

Patient's history, physical examination, thyroid ultrasound guided FNAC studies, experienced thyroid surgeons, endocrinologists and pathologists may help to increase the sensitivity and the diagnostic accuracy to avoid missing a diagnosis of carcinoma or subjecting patients to unnecessary surgery.

Complications of thyroid surgical procedures nowadays have been low with an acceptable morbidity and mortality. Studies indicate that death rate is zero to less than one percent [33-35].

The two national studies from Central region [12] and Western region [15] of Saudi Arabia have reported papillary carcinoma as the commonest type of thyroid cancer, $89 \%$ and $82 \%$ respectively, comparable to the $74 \%$ reported in our study. Morbidity in the Central region was $6.8 \%$ with zero mortality. In the Western region study, mortality was $2.2 \%$. In our study, morbidity and mortality were $18 \%$ and $0.07 \%$ respectively.

The main treatment of thyroid malignant diseases includes total or near-total thyroidectomy, which is the treatment of choice for all types of thyroid cancer except primary thyroid lymphoma. L-thyroxine is essential to suppress TSH especially for papillary and follicular tumors. Radioactive iodine may improve survival in patients with well-differentiated papillary and follicular tumors with certain indications. Our patients were treated with total or near-total thyroidectomy, L-thyroxine suppression or referral to other hospitals.

The permanent complications of surgical intervention are mainly recurrent laryngeal nerve palsy, hypothyroidism and hypoparathyroidism. Follow up of our patients were not consistent, since some patients were referred to other hospitals and others disappeared from follow up. 
However, for those who had follow-up and had no other treatment other than surgical resection and L-thyroxine suppression, $8.8 \%$ had recurrences of thyroid cancer either local or distant. These recurrences occurred within 3 years of follow-up. Two patients with primary thyroid lymphoma were treated with chemotherapy and had no recurrence.

The limitations of our study include the small sample size, its retrospective nature over long period, enrolled patients were managed by different teams, cases were from a single hospital and not all patients had follow up. The findings might therefore, not be reflective of the overall general population.

In conclusion, our study showed that patients in the eastern province of Saudi Arabia with thyroid cancer were seen predominantly in females in a relatively younger population with a median age of 37.8 years. All the patients presented with thyroid nodules, $74 \%$ of which were papillary carcinoma and $73 \%$ were limited to the thyroid tissues. Primary lymphoma of thyroid gland accounted for $4.9 \%$. The specificity was $92 \%$ and the sensitivity $56 \%$. The main surgical complications were not different from other studies.

\section{Acknowledgement}

I would like to extend my sincere gratitude to Professor Abdulaziz Al-Quorain for his valuable contribution and revising the manuscript.

\section{REFERENCES}

[1] Kingdom of Saudi Arabia, Ministry of Health, National Cancer Registry, “Cancer Incidence Report. 1999-2000,” 2004.

[2] T. T. Htwe, M. M. Hamdi, G. K. Swethadri, J. O. L. Wong, M. M. Soe and M. S. Abdullah, "Incidence of Thyroid Malignancy among Goitrous Thyroid Lesions from the Sarawak General Hospital,” Singapore Medical Journal, Vol. 50, No. 7, 2009, pp. 724-728.

[3] S. S. Al Sobhi, "The Current Pattern of Thyroid Surgery in Saudi Arabia and How to Improve It,” Annals of Saudi Medicine, Vol. 22, No. 3-4, 2002, pp. 3-4.

[4] D. S. Ross, "Predicting Thyroid Malignancy," The Journal of Clinical Endocrinology \& Metabolism, Vol. 91, No. 11, 2006, pp. 4253-4255. doi:10.1210/jc.2006-1772

[5] E. L. Mazzaferri, "Thyroid Cancer in Thyroid Nodules: Finding a Needle in the Haystack," The American Journal of Medicine, Vol. 93, No. 4, 1992, pp. 359-362. doi:10.1016/0002-9343(92)90163-6

[6] A. S. Irshad, M. Girivasan, V. Ramesh and J. A. Santhosh, "High Incidence of Thyroid Cancer in Toxic Multinodular Goiters," Asian Pacific Journal of Clinical Oncology, Vol. 3, No. 3, 2007, pp. 119-124. doi:10.1111/j.1743-7563.2007.00108.x

[7] A. Belfiore, G. L. La Rosa, G. A. La Porta, D. Giuffrida,
G. Millazo, L. Lupo, et al., "Cancer Risk in Patients with Cold Thyroid Nodules: Relevance of Iodine Intake, Sex, Age, and Multinodularity,” The American Journal of Medicine, Vol. 93, No. 4, 1992, pp. 363-369. doi:10.1016/0002-9343(92)90164-7

[8] R. A. Delellis, "Pathology and Genetics of Thyroid Carcinoma,” Journal of Surgical Oncology, Vol. 94, No. 8, 2006, pp. 662-669. doi:10.1002/jso.20700

[9] P. Nix, A. Nicolides and A. P. Coatesworth, “Thyroid Cancer Review 1: Presentation and Investigation of Thyroid Cancer," International Journal of Clinical Practice, Vol. 59, No. 11, 2005, pp. 1340-1344. doi:10.1111/j.1368-5031.2005.00671.x

[10] J. Christine, J. Oucharek, D. Learoyd and B. Stan, "Standarad and Emerging Therapies for Metastastic Differentiated Thyroid Cancer,” The Oncologist, Vol. 15, No. 2, 2010, pp. 146-156. doi:10.1634/theoncologist.2009-0190

[11] R. A. Delellis, R. V. Lloyd, P. U. Heitz and C. Eng, "Pathology and Genetics of Thyroid Carcinoma," In: R. A. DeLellis, Ed., Pathology and Genetics of Tumors of Endocrine Organs, IARC Press, Lyon, 2004, pp. 57-66.

[12] F. A. Qari, "Pattern of Thyroid Malignancy at a University Hospital in Western Saudi Arabia," Saudi Medical Journal, Vol. 25, No. 7, 2004, pp. 447-451.

[13] M. Al-Jaradi, A. Sllam, H. Jabr, A. Borda, M. Decaussin-Petruci and N. Berger, "Prevalence of Differentiated Thyroid Cancer in 810 Cases of Surgically Treated Goiter in Yemen,” Annals of Saudi Medicine, Vol. 25, No. 5, 2005, pp. 394-397.

[14] Y. A. Abdulmughni, M. A. Al-Hureibi, K. A. Al-Hureibi, M. A. Ghafoor, A. H. Al-Wadan and Y. A. Al-Hureibi, "Thyroid Cancer in Yemen," Saudi Medical Journal, Vol. 25, No. 1, 2004, pp. 55-59.

[15] S. M. Alsalamah, K. Khalid and H. A. Bismar, "Incidence of Differentiated Cancer in Nodular Goiter," Saudi Medical Journal, Vol. 23, No. 8, 2002, pp. 947-952.

[16] J. K. Chan and D. Saw, “The Grooved Nucleus. A Useful Diagnostic Criterion of Papillary Carcinoma of the Thyroid,” American Journal of Surgical Pathology, Vol. 10, No. 10, 1986, pp. 672-629. doi:10.1097/00000478-198610000-00002

[17] C. D. Scopa, "Histopathology of Thyroid Tumors. An Overview,” HORMONES, Vol. 3, No. 2, 2004, pp. 100110.

[18] E. Tuncel, C. Ersoy, E. Erturk and S. Imamoglu, "Retrospective Analysis of Histopathological Pattern of Thyroid Cancer in Southern Maramara Region of Turkey and Comparison of the Data of Previous Decade,” Turkish Journal of Endocrinology and Metabolism, Vol. 2003, No. 3, pp. 107-111.

[19] H. B. Burch, "Evaluation and Management of Solid Thyroid Nodule," Endocrinology Metabolism Clinics of North America, Vol. 24, No. 4, 1995, pp. 663-710.

[20] N. Hussain, M. Anwar, N. Nadia and Z. Ali, "Pattern of Surgically Treated Thyroid Diseases in Karachi," Biomedica, Vol. 21, 2005, pp. 18-20.

[21] Y. A. Abdul Mughni, M. A. Al-Hureibi, K. A. Al-Huriebi, M. A. Ghafoor, A. H. Al-Wadan and Y. A. Al-Hureibi, 
“Thyroid Cancer in Yemen,” Saudi Medical Journal, Vol. 25, No. 1, 2004, pp. 55-59.

[22] A. Z. Khan, S. A. Naqi, A. Kamal and K. J. Abaid, “Thyroidectomy in Carcinoma of Thyroid, a THREE Years Experience,” Annals, Vol. 10, No. 4, 2004, pp. 368-369.

[23] A. Elhamel, I. H. Sharif and S. A. Wassef, "The Pattern of Thyroid Disease in a Closed Community of 1-1/2 Million People,” Saudi Medical Journal, Vol. 9, No. 5, 1988, pp. 481-484.

[24] M. Ahmad, B. Al Saihati, W. Greer, A. Al-Nuaim, S. Bakheet, A. M. Abdulkareem, et al., "A Study of 875 Cases of Thyroid Cancer Observed over a Fifteen-Year Period (1975-89) at the King Faisal Specialist Hospital and Research Centre,” Annals of Saudi Medicine, Vol. 15, 1995, pp. 579-584.

[25] D. Sarne and A. B. Schneider, "External Radiation and Thyroid Neoplasia," Endocrinology \& Metabolism Clinics of North America, Vol. 25, No. 1, 1996, pp. 181-195. doi:10.1016/S0889-8529(05)70318-2

[26] S. A. Hundahl, B. Cady, M. P. Cunningham, E. Mazzaferri, R. F. Mckee, J. Rosai, et al., "Initial Results from a Prospective Cohort Study of 5583 Cases of Thyroid Carcinoma Treated in the United States during 1996. US and German Thyroid Cancer Study Group. An American College of Surgeons Commission on Cancer Patients Evaluation Study," Cancer, Vol. 89, No. 1, 2000, pp. 202-217. doi:10.1002/1097-0142(20000701)89:1<202::AID-CNCR 27>3.0.CO;2-A

[27] C. Freeman, J. W. Berg and S. J. Cutler, “Occurrence and Prognosis of Extra-Nodal Lymphoma,” Cancer, Vol. 29, No. 1, 1972, pp. 252-260. doi:10.1002/1097-0142(197201)29:1<252::AID-CNCR28 20290138>3.0.CO;2-\#

[28] C. Thieblemont, A. Mayer, C. Dumontet, E. Barbier, P. Callet-Bauchu, F. Felman, et al., "Primary Thyroid Lymphoma Is Heterogeneous Disease,” The Journal of Clini- cal Endocrinology \& Metabolism, Vol. 87, No. 1, 2002, pp. 105-111. doi:10.1210/jc.87.1.105

[29] V. A. Livolsi, K. Montone and M. Sack, "Pathology of Thyroid Gland,” In: S. S. Sternberg, Ed., Diagnostic Surgical Pathology, Lipincott Williams and Wilkins, Philadelphia, 1999, pp. 529-587.

[30] J. Cap, A. Ryska, P. Rehorkova, E. Hovorkova, Z. Kerekes and D. Pohnetalova, "Sensitivity and Specificity of the Fine Needle Aspiration Biopsy of the Thyroid. Clinical Point of View," Clinical Endocrinology (Oxford), Vol. 51, No. 4, 1999, pp. 509-515. doi:10.1046/j.1365-2265.1999.00847.x

[31] J. M. Miller, J. I. Hamburger and S. Kini, "Diagnosis of Thyroid Nodules: Use of Fine Needle Aspiration and Needle Biopsy," The Journal of the American Medical Association, Vol. 241, No. 5, 1979, pp. 481-484. doi:10.1001/jama.1979.03290310021006

[32] R. D. Bapat, S. H. Shah, R. G. Relekar, A. Pandit and S. D. Bhandarka, “Analysis of 105 Uninodular Goitres,” Journal of Postgraduate Medicine, Vol. 3, No. 2, 1992, pp. 60 61.

[33] W. C. Pederson, C. L. Johson, H. V. Gaskill III, J. B. Aust and A. B. Cruz Jr., "Operative Management of Thyroid Disease," The American Journal of Surgery, Vol. 148, No. 3, 1984, pp. 350-352. doi:10.1016/0002-9610(84)90469-0

[34] J. Herranz-González, J. Gavilán, J. Martinez-Vidal and C. Gavilán, "Complications following Thyroid Surgery," Archives of Otolaryngology_Head \& Neck Surgery, Vol. 117, No. 5, 1991, pp. 516-518. doi:10.1001/archotol.1991.01870170062014

[35] J. C. Filho and L. P. Kowalski, "Postoperative Complications of Thyroidectomy for Differentiated Thyroid Carcinoma," American Journal of Otolaryngology_Head and Neck Medicine and Surgery, Vol. 25, No. 4, 2004, pp. 225230. doi:10.1016/j.amjoto.2004.02.001 